\title{
Overcoming the Existing Challenges in the Eastern Mediterranean Region in the Fight Against COVID-19
}

\author{
(1) Saurabh Shrivastava, ${ }^{1}$ (1) Prateek Shrivastava²
}

'Department of Community Medicine, Member of the Medical Education Unit and Institute Research Council, Shri Sathya Sai Medical College \& Research Institute, Sri Balaji Vidyapeeth; Deemed to be University, Ammapettai, Nellikuppam, Chengalpet District, Tamil Nadu, India ${ }^{2}$ Department of Community Medicine, Shri Sathya Sai Medical College \& Research Institute, Sri Balaji Vidyapeeth; Deemed to be University, Ammapettai, Nellikuppam, Chengalpet District, Tamil Nadu, India

\section{ABSTRACT}

The cases of Corona Virus Disease-2019 (COVID-19) have been reported across all the regions of the world, with the European region and the American region being the most affected. Even though the current estimates pertaining to the outbreak in the Eastern Mediterranean appear significantly less in comparison to the global scenario, but we still have to acknowledge COVID-19 as a major cause of public health concern in the region. This is predominantly because most of the recently affected nations have been experiencing one or the other form of humanitarian emergencies resulting due to wars or conflicts. The presence of all these factors has significantly affected the various prevention and control dimensions, and the delay has been reported in the detection of cases, their isolation and contact tracing. In conclusion, in the fight against COVID-19 pandemic in the Eastern Mediterranean region, many strengthening and capacity building activities need to be carried out. It is the responsibility of the political leaders to acknowledge the prevailing vulnerabilities and accept a ceasefire and work together to reduce the risk of COVID-19 within their settings.

Keywords: COVID-19, infection, World Health Organization

\section{INTRODUCTION}

The cases of Corona Virus Disease-2019 (COVID-19) have been reported across all the regions of the world, with the European region and the American region being the most affected. ${ }^{[1]}$ The global estimates suggest that a total of 3018952 cases has been reported, while 207973 people have succumbed to the novel viral infection worldwide, which amounts for a global case fatality rate of $6.88 \% .{ }^{[1]}$ In the Eastern Mediterranean region, to date, 176928 cases and 7304 deaths have been notified across 21 of the affected nations in the region, while Iran and Saudi Arabia together account for a significant proportion of the incident cases. ${ }^{[1]}$

Accepted Date: 12.05 .2020

Published online: 21.08 .2020

(C) Copyright 2020 by Anatolian Journal of Family Medicine -

Available online at Www.anatoljfm.org

OPEN ACCESS

\section{COVID-19 in Eastern Mediterranean Region: Existing Challenges}

Even though the current estimates about the outbreak in the Eastern Mediterranean appear significantly less in comparison to the global scenario, but we still have to acknowledge COVID-19 as a major cause of public health concern in the region. ${ }^{[2]}$ This is predominantly because of the recent detection of the virus in nations like Syria, Libya and Yemen, wherein no cases were reported initially. All these three nations have been experiencing one or the other form of humanitarian emergencies resulting due to wars or conflicts and have been there for such 
a long time that the nations have a very weak health care delivery system, with a significant shortage of the health workforce and the general population is deprived of the most basic and essential health and welfare services. ${ }^{[2,3]}$

The epidemiological findings of the disease have indicated that the infection is transmitted between humans due to close contacts and through droplets and thus the most effective way of prevention of acquisition or onward transmission of infection is through maintaining physical distancing and strictly adhering to the infection prevention and control measures (viz. frequent handwashing, respiratory hygiene, use of masks by respiratory symptomatic, environmental cleaning and disinfection) ${ }^{[2-4]}$ From the public health perspective, the situation is extremely challenging as the majority of the citizens are living in the overcrowded settings, with poor food security, and lack of access to the improved water supply-sanitation and hygiene facilities. The presence of these attributes interferes with the maintenance of personal hygiene and also exposes the people to a heightened risk of acquisition of infection..$^{[2,3]}$

Further, owing to the continuation of long-term conflicts, many of the health care facilities have been targeted and destroyed, and the condition has resulted in a significant negative impact even on the treatment of long-term illnesses. The clinical data obtained from COVID-19 patients have revealed that the chances of a poor treatment outcome, including death, is quite common among people who are suffering from chronic illnesses. ${ }^{[2]}$ As a significant proportion of these people do not have access to adequate treatment of their chronic illnesses, the outcome of the COVID-19 infection among these individuals would not be encouraging. Finally, due to the ongoing conflicts, even the sharing of important information to the general population has not been happening in a transparent fashion, and thus, the vulnerable population groups will be paying the price for the lack of access to reliable information. ${ }^{[2]}$

The presence of all these factors has significantly affected the various prevention and control dimensions, and the delay has been reported in the detection of cases, their isolation and contact tracing. ${ }^{[2,3]}$ At the same time, there has been not adequate infrastructure available for the isolation of cases and quarantine of the contacts. Further, a significant shortage of personal protective equipment and ventilators is expected to surface once the number of the cases start rising.

\section{Encouraging Signs and the Areas to be Strengthened}

The good thing is that the rise in the number of cases in the region is not much and it gives us an opportunity to bridge the existing gap by strengthening the prevailing loopholes in the essential domains. ${ }^{[1]}$ The public health authorities should develop liaison with the private sector to expand the reach of diagnostic services, cover the vulnerable population groups and strengthen contact tracing ${ }^{[4]}$ Further, a series of training programs have been organized in the region to create awareness about the disease and what all needs to be done to reduce the spread of the infection..$^{[5]}$ In addition, the existing framework of surveillance, which is being utilized for other diseases, should be simultaneously utilized for COVID-19 to keep track of the trends. Further, sound risk communication and community engagement plan need to be formulated to provide the people with the desired information and eliminate the possibility of myths and spreading of rumors about the disease. ${ }^{[4,5]}$

It is a welcome sign that some of the nations have started to implement the exit strategy within their jurisdictions, but the health authorities should go about the task in a scientific approach and be prepared for the sudden upsurge in cases. However, it is important to accept that we cannot accomplish sustainable gains unless the efforts are led by the leaders and well-supported by the whole of the community and with the support of each and every stakeholder, including the different conflicting parties. ${ }^{[2-5]}$

\section{CONCLUSION}

In conclusion, in the fight against COVID-19 pandemic in the Eastern Mediterranean region, many strengthening and capacity building activities need to be carried out. It is the responsibility of the political leaders to acknowledge the prevailing vulnerabilities and accept a ceasefire and work together to reduce the risk of COVID-19 within their settings.

\section{Disclosures}

Peer-review: Externally peer-reviewed.

Conflict of Interest: None declared.

Authorship Contributions: Concept - S.R.S.; Design - S.R.S., P.S.S.; Supervision - S.R.S., P.S.S.; Analysis and/or interpretation S.R.S., P.S.S.; Literature search - P.S.S.; Writing - S.R.S.; Critical review - S.R.S., P.S.S.

\section{REFERENCES}

1. World Health Organization. Coronavirus disease 2019 (COVID-19)Situation Report - 100. Available at: https://www.who.int/docs/default-source/coronaviruse/situation-reports/20200429-sitrep-100-covid-19. pdf?sfvrsn=bbfbf3d1_2. Accessed Jun 17, 2020.

2. World Health Organization. Statement by WHO's Regional Director Dr Ahmed Al-Mandhari on our collective fight against 
COVID-19. Available at: http://www.emro.who.int/media/ news/statement-by-whos-regional-director-dr-ahmed-almandhari-on-our-collective-fight-against-covid-19.html. Accessed Jun 17, 2020.

3. Al-Tawfiq JA, Memish ZA. COVID-19 in the Eastern Mediterranean Region and Saudi Arabia: prevention and therapeutic strategies. Int J Antimicrob Agents 2020;55:105968.

4. World Health Organization. 2019 Novel Coronavirus
(2019-nCoV): Strategic preparedness and response plan. Geneva: WHO press; 2020. p. 1-20.

5. Al Nsour M, Bashier H, Al Serouri A, Malik E, Khader Y, Saeed $K$, et al. The Role of the Global Health Development/Eastern Mediterranean Public Health Network and the Eastern Mediterranean Field Epidemiology Training Programs in Preparedness for COVID-19. JMIR Public Health Surveill 2020;6:e18503. 